\title{
El espacio público y los centros comerciales*
}

\author{
Public space and shopping centers
}

\author{
Felipe Chumpitaz Mellarez** \\ Investigador independiente \\ Recibido: 8 de octubre de 2020 \\ Aceptado: 15 de noviembre de 2020
}

Para opinar acerca de una relación entre dos espacios, es importante evaluar el comportamiento de ambos, un hecho que deviene en el análisis de manifestaciones culturales a través del tiempo, la situación actual y, quizás, atreverse a proyectar lo que podría acontecer en el futuro, siempre en términos condicionales, toda vez que lo menos predecible son las tendencias del comportamiento humano. Sobre todo, cuando no existe un plan que lo encamine, porque no se cuenta con los medios y los recursos económicos para llevarlo adelante o por ser este extremadamente complejo por la diversidad y cantidad de factores a tomar en cuenta para su aplicación eficiente.

En principio, un espacio público se proyecta esencialmente hacia la atención de los derechos y necesidades sociales de los ciudadanos, mientras que la razón de ser de un centro comercial es la búsqueda de consumidores. Sin embargo, a pesar de sus diferencias, entre el espacio público y los centros comerciales, se han generado diversas conexiones. $Y$ aunque los centros comerciales surgieron con una expresa voluntad de independencia y autonomía, determinada por los intereses económicos del sector privado, con el transcurrir de las décadas se fue transformando en una entidad complementaria de los espacios públicos, en la medida que ambos convocan a una creciente población en sus variados comportamientos y necesidades, más allá de su origen.

Esto no significa que la relación deje de ser competitiva: el afán de la venta masiva al por menor -verdadera alma de los centros comerciales- es el de acoger el mayor flujo de población dentro de sus linderos. Además, no se descarta que esta relación pueda llegar a ser parasitaria, si anotamos que la inserción de uno en el otro se produce cuando una entidad trata de aprovechar las debilidades funcionales de la otra. Esto no ocurre si una ciudad está debidamente planificada y cada quien cumple con el papel que le corresponde, pero, mientras no cambien ciertas estructuras legales y criterios en el diseño, manejo y comercialización del suelo urbano, será una situación inevitable.

\footnotetext{
* Antecedentes del documento. El artículo es de lectura independiente pero se elabora como parte de un trabajo de investigación, para futura publicación, referente al tema de retail. Es resultado de la propia experiencia profesional como partícipe en la implementación de espacios comerciales.

** Felipe Chumpitaz Mellarez. Arquitecto (Universidad Nacional de Ingeniería).
} 
Contrariamente a lo que se pueda pensar, el centro comercial, como se aprecia actualmente, no nació como una tipología de absoluto interés mercantil. Su creador, el arquitecto suizo Víctor Gruen, proponía integrar a las grandes superficies del Southdale Mall en Minnnesota (1956), áreas de uso educativo, cultural, deportivo y hasta de salud, con el propósito de instalar en un solo lugar los mejores servicios de una ciudad. Lamentablemente, esto fue descartado para dar prioridad a la venta, a la recreación y al estacionamiento vehicular, lo cual generó un resentimiento que el diseñador llevó hasta el final de sus días. ${ }^{1}$ Ciertamente, hoy asistimos al retorno a dicho planteamiento, no necesariamente coincidente con los principios altruistas del arquitecto Gruen, sino debido a un afán de modernización y revitalización que favorezca y fortalezca la afluencia del público comprador.

Pero, haciendo en este punto un feed back de lo que ha sucedido con el espacio público, debemos reconocer que, habiendo sido el espacio público desde su más remoto origen un lugar de interacción social, política, cultural y, en muchos casos, eminentemente comercial, este ha sufrido los avatares de incompetencias simultáneas y sucesivas que han propiciado su declive. Por un lado, las autoridades implicadas en su desarrollo, cuando no han podido consolidar y sacar adelante proyectos integrales que trasciendan la periodicidad del ejercicio municipal y/o gubernamental $y$, por otra parte, los profesionales que no han logrado sustentar ni defender proyectos con los alcances que la coyuntura exige, cuya responsabilidad radica en la insuficiente capacidad de gestión para hacerlos realidad.

Es cierto que en Latinoamérica se han dado algunos casos a tomar en cuenta; sin embargo, esto no alcanza para considerar que están dados los lineamientos de una política de mejoramiento o revitalización del espacio urbano, aplicable a realidades similares, con sus respectivas adecuaciones de detalle. Es importante señalar que la factibilidad de una transformación urbana sostenida y sostenible requiere de la contribución de los gobiernos central y municipal, los colegios profesionales, las universidades y la participación ciudadana, para señalar a los de mayor protagonismo, sin ser excluyentes con otros aportantes. Porque aun cuando el conocimiento académico pueda estar en manos de los especialistas, ni su intervención ni las experiencias de otras latitudes son suficientes para prescindir del usuario de la ciudad. En esta

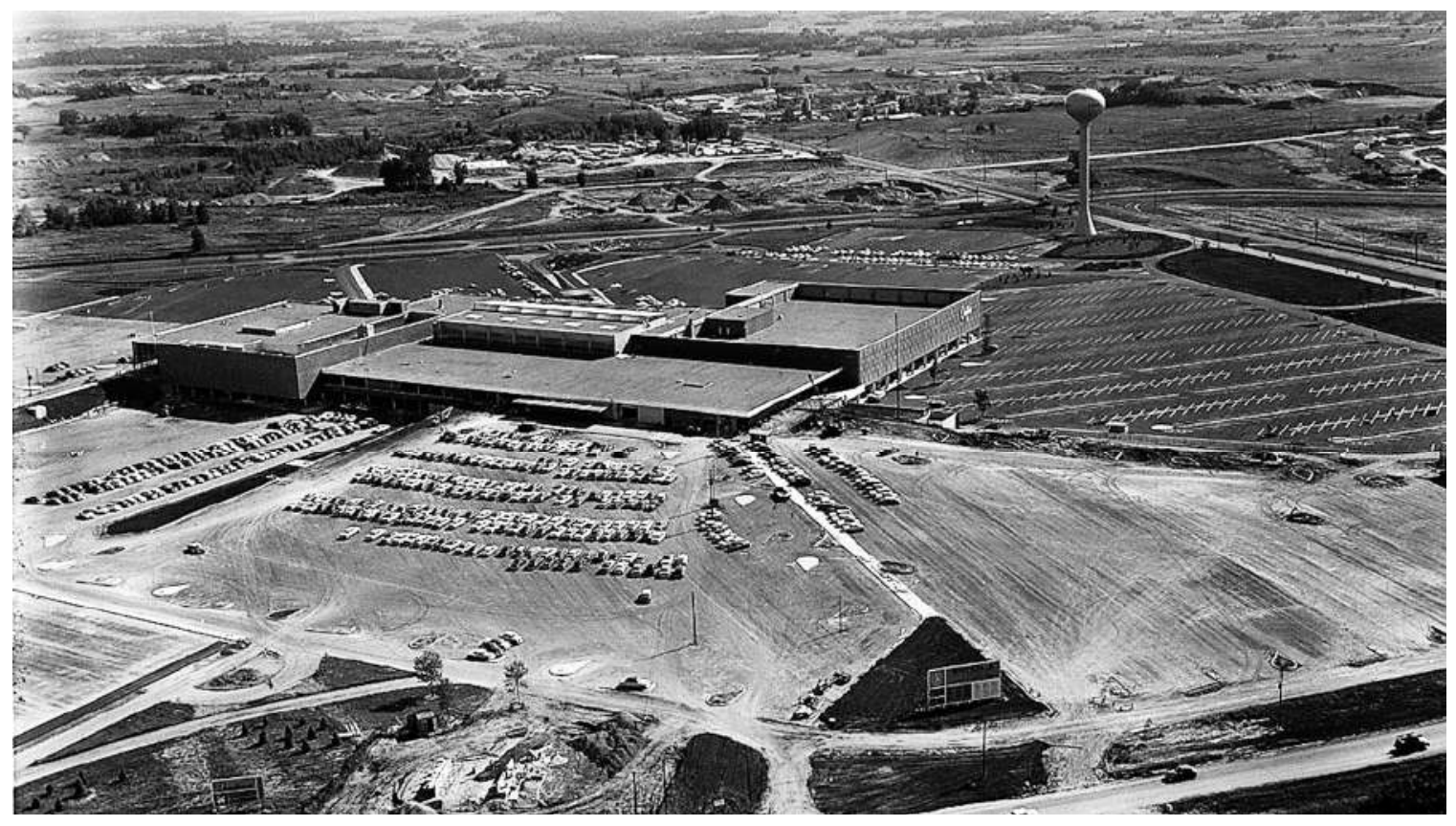

Southdale Mall en Minnesota. Diseño de Víctor Gruen, 1956. Fuente: Foto Google 


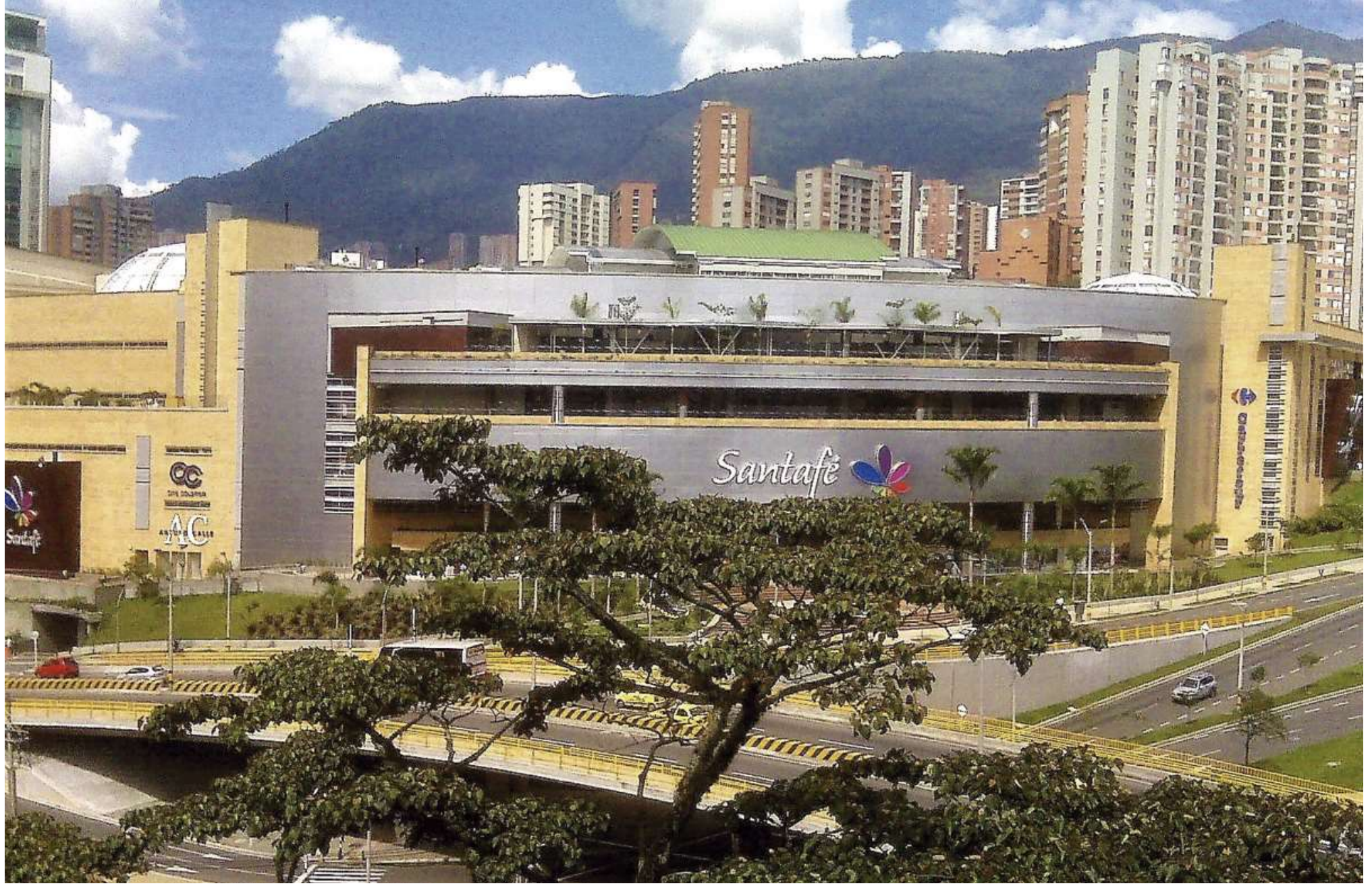

Centro Comercial Santafé de Medellín. Foto Felipe Chumpitaz M., 2012

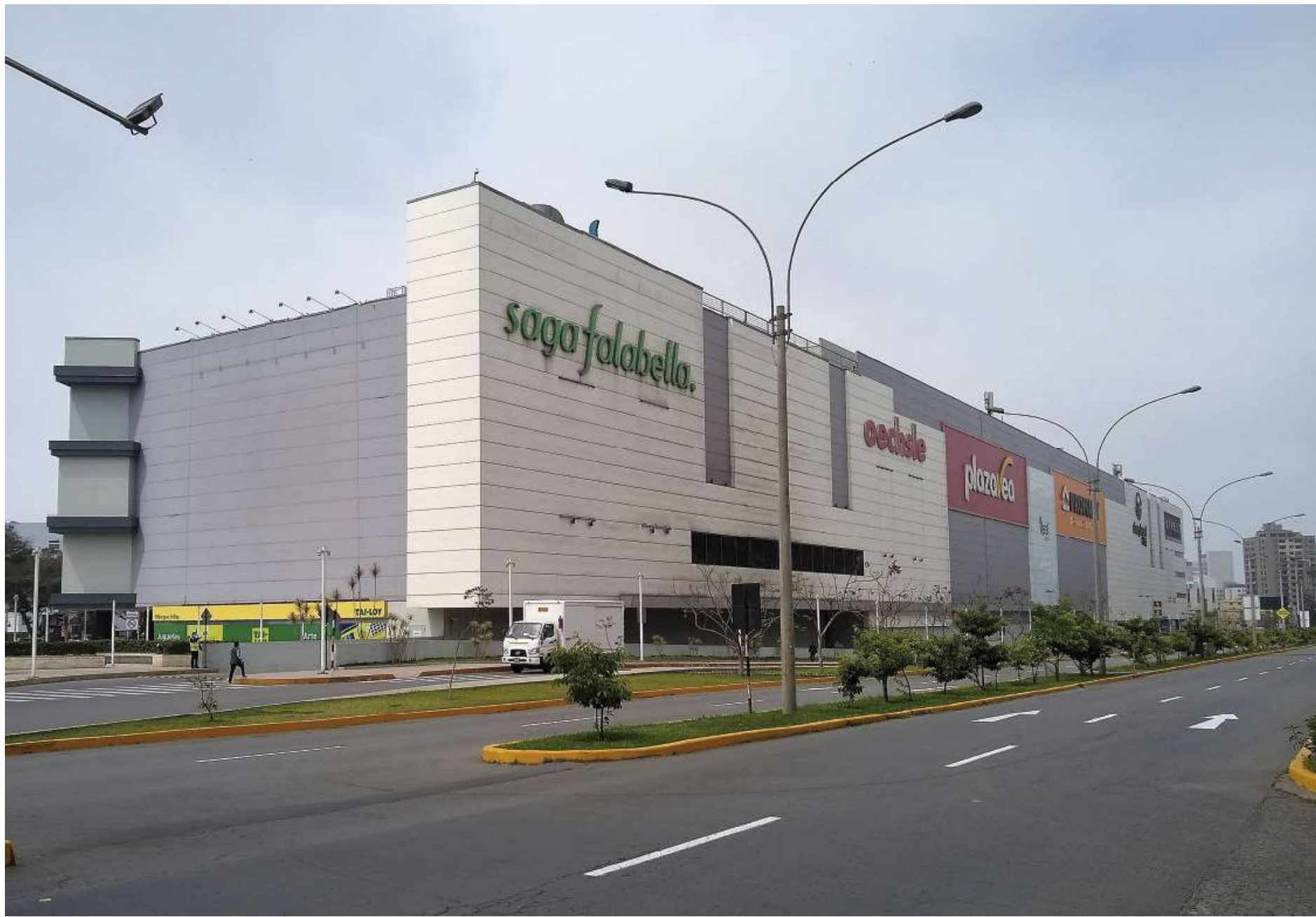


problemática van de la mano, entre otros, el urbanismo, la arquitectura, la sociología, la antropología, la psicología, apoyados por un potente proyecto de educación en general y cívico en especial, sin el cual nada de lo anterior funcionaría como se podría aspirar.

El espacio público debería ser seguro, dimensionado para su eficiente uso por personas de cualquier edad, género y condición física, transitable peatonalmente con comodidad, tener zonas con protección de la intemperie, libre de tránsito vehicular motorizado, acogedor y propio para la conversación, la reflexión, el descanso, el intercambio de opiniones o la discusión de ideas, es decir democrático en el más amplio sentido de la palabra. Lamentablemente, la realidad nos revela que no es así.

Por su parte, ¿qué ha pasado con el comercio? Habiendo sido un importante protagonista desde los albores de la civilización, a través de sus manifestaciones de intercambio de bienes y servicios, el primer centro comercial de los EEUU construido a partir de la segunda mitad del siglo XX, se diseñó con indiferencia y autonomía respecto al espacio público, proponiendo edificaciones que funcionaban absolutamente independientes de su entorno. Sus diseños estaban basados en el confort climático, que fue posible gracias a la novedad tecnológica que significó el aire acondicionado y, con posteridad, las escaleras electro mecánicas. Este hermetismo formal permitía un mayor y mejor uso de las superficies verticales, controlaba el asoleamiento como agente negativo para los productos y se consideraba, incluso, que el mantenimiento de los locales era más económico.

Más adelante, se fueron agregando propuestas de carácter decorativo, con la incorporación de elementos que se asemejaran a la naturaleza, pero absolutamente artificiales. Poco a poco, la tecnología y el descubrimiento de nuevos materiales fueron dando a los diseñadores instrumentos para hacer realidad sus objetivos de innovación y creatividad, hasta llegar a los tiempos modernos, en los que usando la inteligencia artificial, la realidad virtual (y aumentada), la robótica y otros conceptos más ligados a la sostenibilidad, como el green building, en el que destacan el uso de energía solar y renovable, el reciclado de materiales y la reutilización de aguas servidas, procuraron hacer de la compra "una experiencia diferente", que abarcara y conquistara a través de todos los sentidos; y que, además, contrarrestara una tendencia no menor, como es el accionar de los millenials, decididos a mover el mundo desde sus dispositivos móviles.

A diferencia de las entidades públicas, el sector privado en su rubro comercial, específicamente lo que se entiende por retail ${ }^{2}$, ha venido invirtiendo ingentes cantidades de dinero en la revitalización, renovación y actualización de su operatividad e imagen. Cuando una marca no crece físicamente implementando nuevos locales, se transforma y/o se regenera, pero está en un constante movimiento, porque es lo que le demanda el consumidor, buscando fidelizar por un lado a la clientela cautiva pero además tratando de ampliar sus fronteras de atención, sean estas físicas o virtuales. Estas renovaciones suelen darse en plazos que van de 3 a 5 años, períodos dentro de los cuales, la novedad espacial, a pesar de los cambios cosméticos estacionales, van decayendo en su función convocante y resulta urgente repotenciar la expectativa del público.

Pero entonces, ¿qué sucede con el ciudadano que no es atraído por la oferta comercial? La vida no se agota en uno o varios días de shopping, pues aunque para algunos así sea, existe una mayoría poblacional que requiere espacios de intercambio social, político y cultural, que abarquen y atiendan eficientemente toda posibilidad de actividad humana. Esto, en atención al derecho ciudadano a vivir, sentir, disfrutar, intercambiar ideas con sus semejantes y tomar decisiones respecto a su destino, con las implicancias y alcances de lo que significa, en tanto que no encuentra en su entorno inmediato o mediato las condiciones físicas y sociales para resolver y estimular una parte significativa de su desarrollo personal, ni el ámbito donde reconocer el respeto de su condición ciudadana. Podemos ser testigos de loables intentos en algunos distritos $o$ 


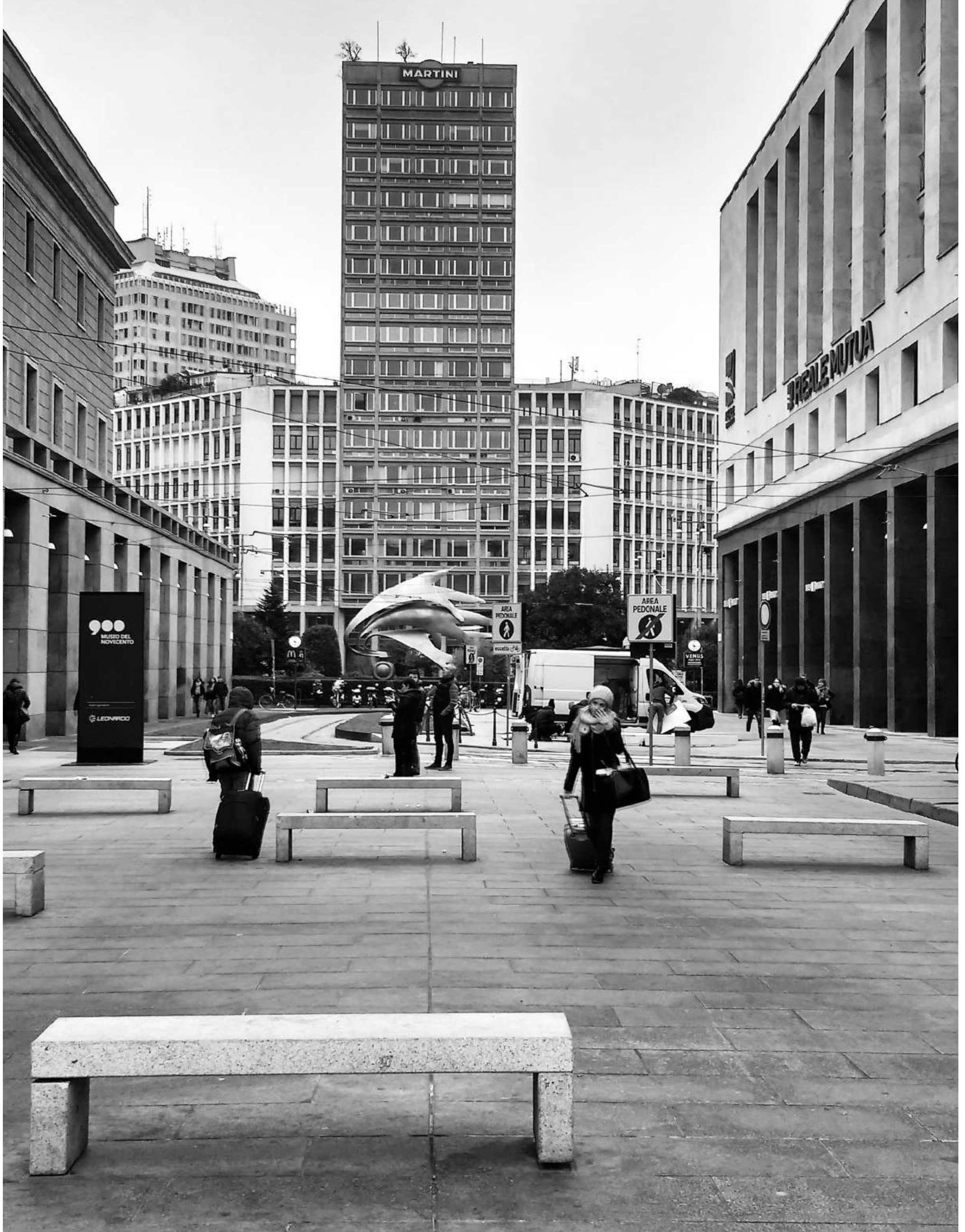


sectores de la ciudad, pero esto no es suficiente ni en lo social, ni en la morfología física urbana, ni en el tiempo de aplicación para calificar que la situación funciona de manera apropiada, adecuada o eficiente. Aquí, debemos señalar con preocupación, cómo un buen número de autoridades y profesionales subordinados consideran que trabajar el espacio público es tomar decisiones únicamente sobre la parte física del urbanismo, es decir, arreglando pistas y veredas, monumentos y áreas verdes; comenzando bien el camino, pero errando la ruta para llegar a objetivos contundentes y permanentes.

El centro comercial, como los complejos culturales, centros cívicos, villas deportivas, vías, calles y plazas, edificios públicos y privados, trama y equipamiento urbano, políticas de tránsito, educación cívica, constituyen las partes de un todo que, para funcionar adecuadamente, deben ser pensados y diseñados para interactuar entre ellos, cumpliendo cada uno su rol independiente con propiedad y eficiencia, pero, a la vez, complementándose para ofrecer los servicios y las atenciones con la idoneidad que la ciudadanía requiere.

No existe competencia posible entre lo que deba ejecutarse en el ámbito público y los planes convocantes del sector privado comercial, pero es evidente que ambos centrarán su foco en el comportamiento del individuo como usuario y cliente. Aparecerán nuevos centros comerciales, cada vez más ambiciosos y generosos en áreas básicamente recreativas y de esparcimiento familiar, que, teniendo en cuenta la reiteración de la práctica, copiarán modelos de realidades geográficas distintas, sin importar las condiciones climáticas de las ciudades en las que serán construidos y tomando como ejemplo lo que se está haciendo en Europa y algunos países asiáticos.

Es muy posible que, con un país reactivado económicamente y con una importante inyección de dinero, comencemos a ver propuestas con áreas exteriores comerciales, cada vez más parecidas a la escena urbana, e incluso rural, por la configuración de vías y plazas, lagos y puentes artificiales, procurando una especie de oasis inserto en el caos urbano, liderado por el inmanejable tráfico vehicular y secundado eficientemente por la contaminación visual, sonora y ambiental del entorno. Pero, ¡cuidado! que esta oferta llegará solo hasta donde el presupuesto del operador del centro comercial lo disponga. Incorporar aparte de parques de diversiones, ríos artificiales, acuarios gigantes, que nos den la impresión que incursionamos en el mundo marino, estructuras a escala de las diferentes actividades productivas de una sociedad para que los niños tengan una idea de lo que hacen sus padres, entre muchas otras propuestas, podrían dar lugar a una burbuja de confort familiar que se quedaría en la superficialidad y corta temporalidad de sus efectos, generando frustraciones e inevitables segregaciones contraproducentes y distorsionantes para el desarrollo de una localidad. $Y$ es que el sector privado, dentro de sus predios, puede hacer lo que mejor le parezca, salvaguardando sus derechos e intereses.

Por otro lado, lo que debiera hacer la ciudad es equilibrar la balanza, no por comparación como por obligación, con decisiones, acciones y proyectos que fortalezcan al espacio público, no en competencia de divertimento, sino más bien en fomentar valores culturales, educativos, deportivos, sociales y políticos del quehacer diario, atacando de lleno la problemática real que es mucho mayor al tema comercial.

El espacio público, en su relación con la propiedad privada, sea esta residencial, comercial, industrial o la que fuere, forma parte de una realidad física y ocupacional que demanda una propuesta integral $y$, como tal, debe manejar variables que sirvan para orientar y encaminar el crecimiento sostenido y planificado de las ciudades, pero apartándose de dogmas, que consideran el conocimiento teórico como único instrumento válido para proponer soluciones.

La participación ciudadana debe cumplir un rol sino principal, por lo menos determinante, ya que como usuarios finales del espacio, la dinámica o revitalización de un lugar será un éxito en la medida que la comunidad debidamente organizada haga uso de su derecho de opinión, contando 


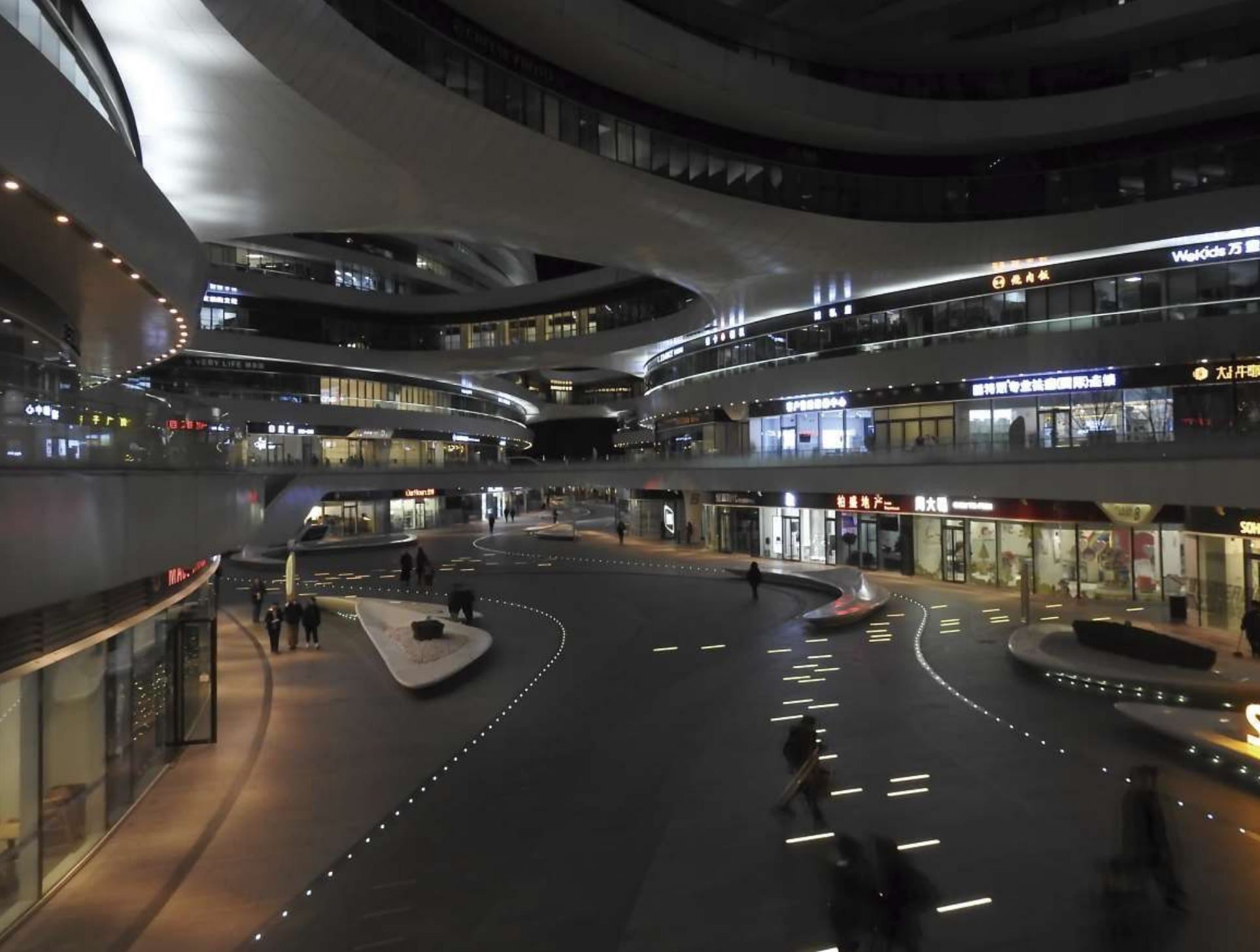

Galaxy Soho Pekín. Foto Miguel Muñoz Li, 2019.

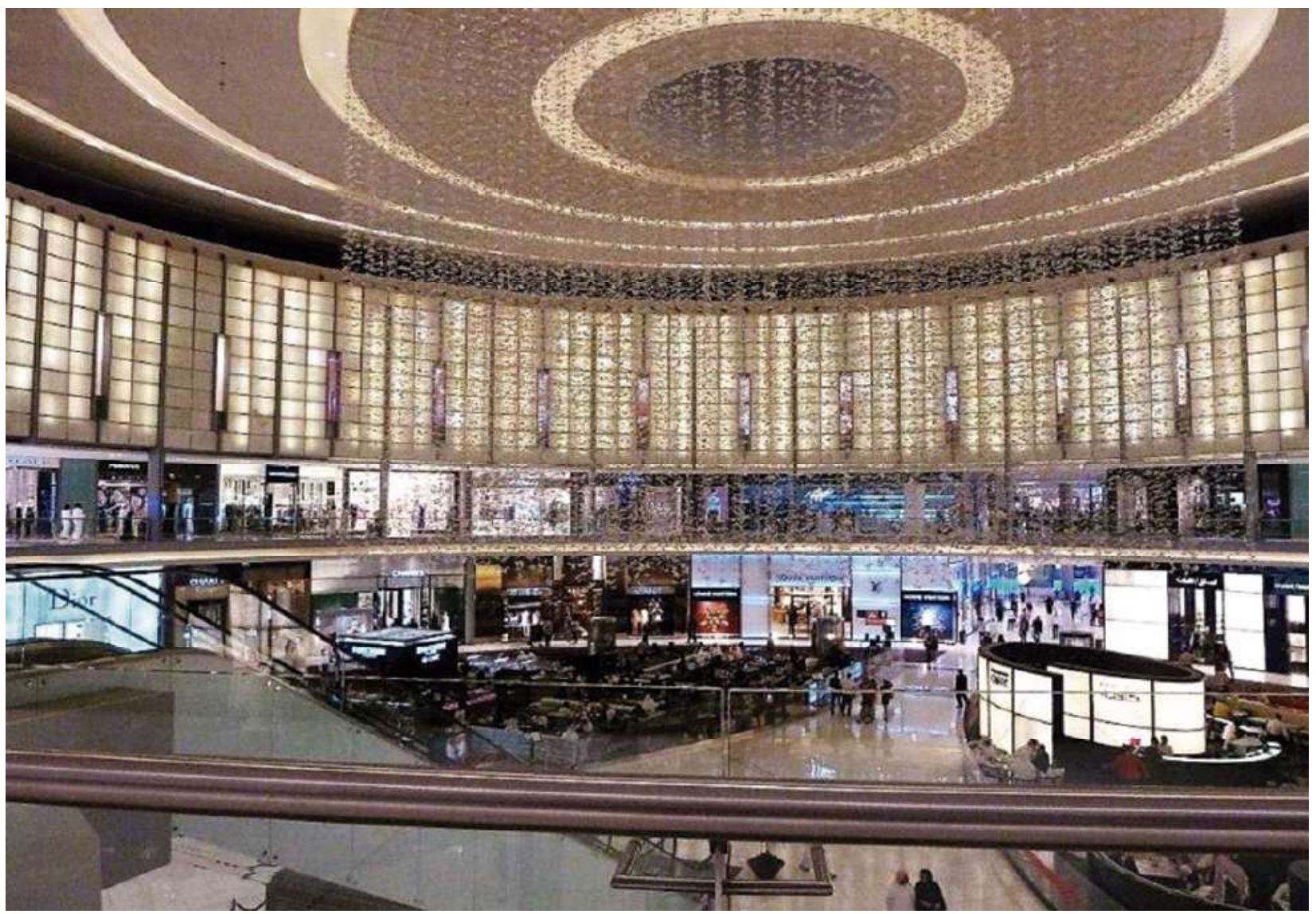




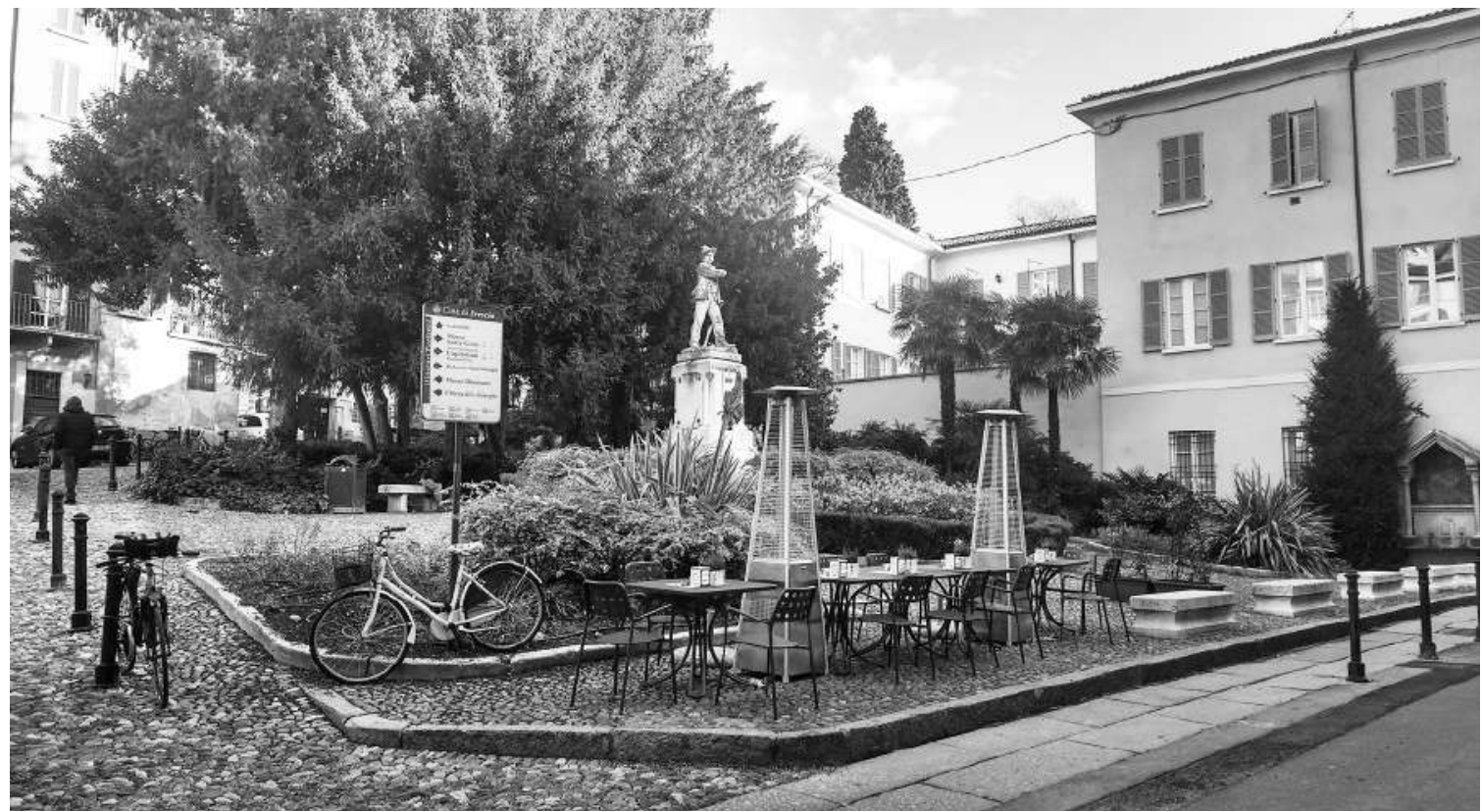

Brescia. Foto Felipe Chumpitaz M., 2018

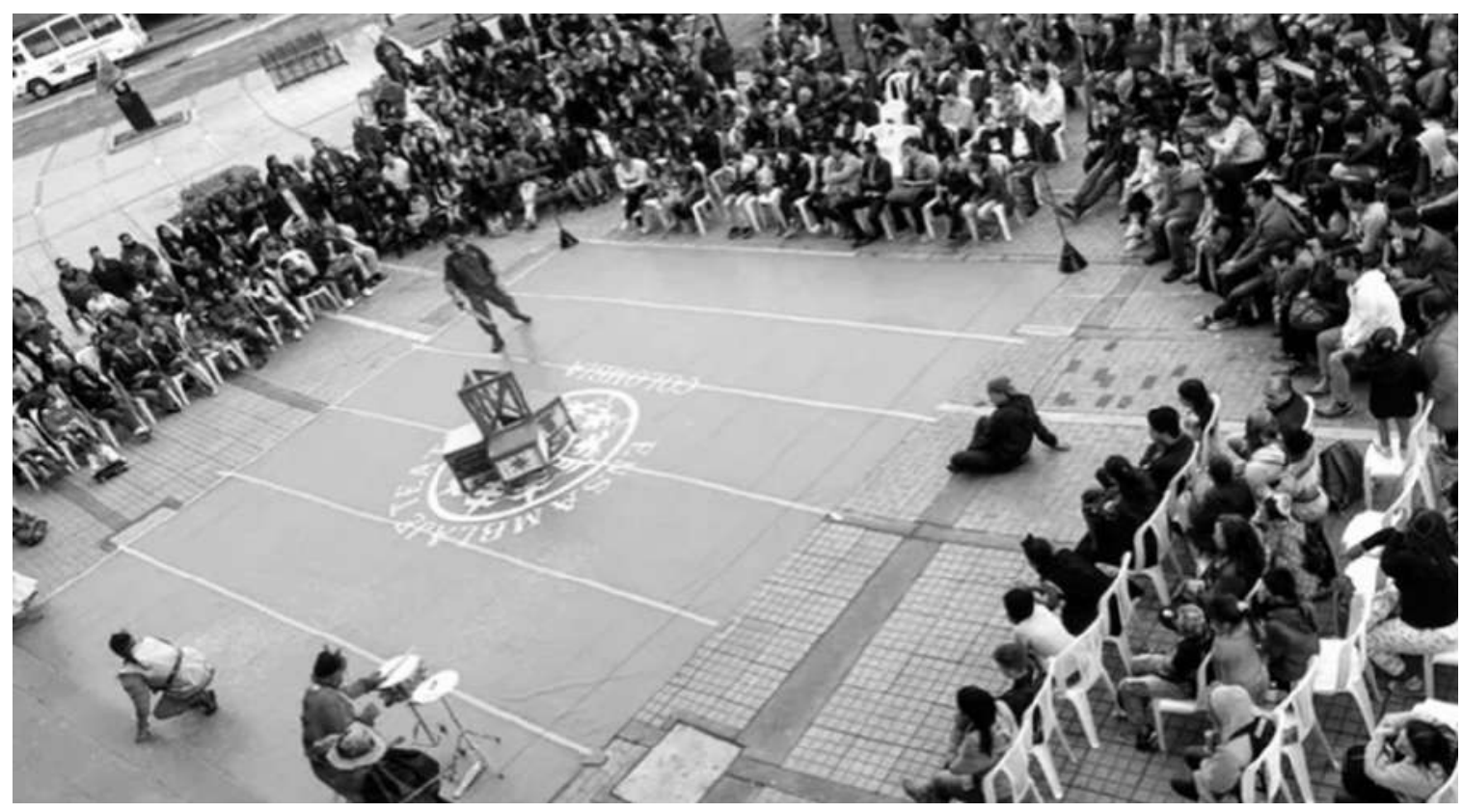

Parque Cultural de Mosquera. Bogotá. Festival del año 2018. Fuente: Diario El Espectador

con el "paraguas" de legislaciones adecuadas, autoridades competentes y éticamente comprometidas con el presente y el futuro de la urbe, en una guerra franca contra los apetitos desmedidos de quienes, en el sentido más lumpen, trafican con terrenos, o quienes, con cuello y corbata, pretenden hacer del suelo, una torta que se van a repartir a su gusto porque son ellos los que la cortan.

\section{La función compartida}

Un buen ejemplo de lo que puede lograrse a partir de una gestión que propicie la coparticipación del sector público y el sector privado, solo por citar un caso que tuvimos la oportunidad de experimentar, ha sido el Festival Iberoamericano de Teatro en Bogotá, cuya primera versión se llevó a cabo en 1988 y, en períodos bienales, ha llegado a cumplir treintaidós años. 


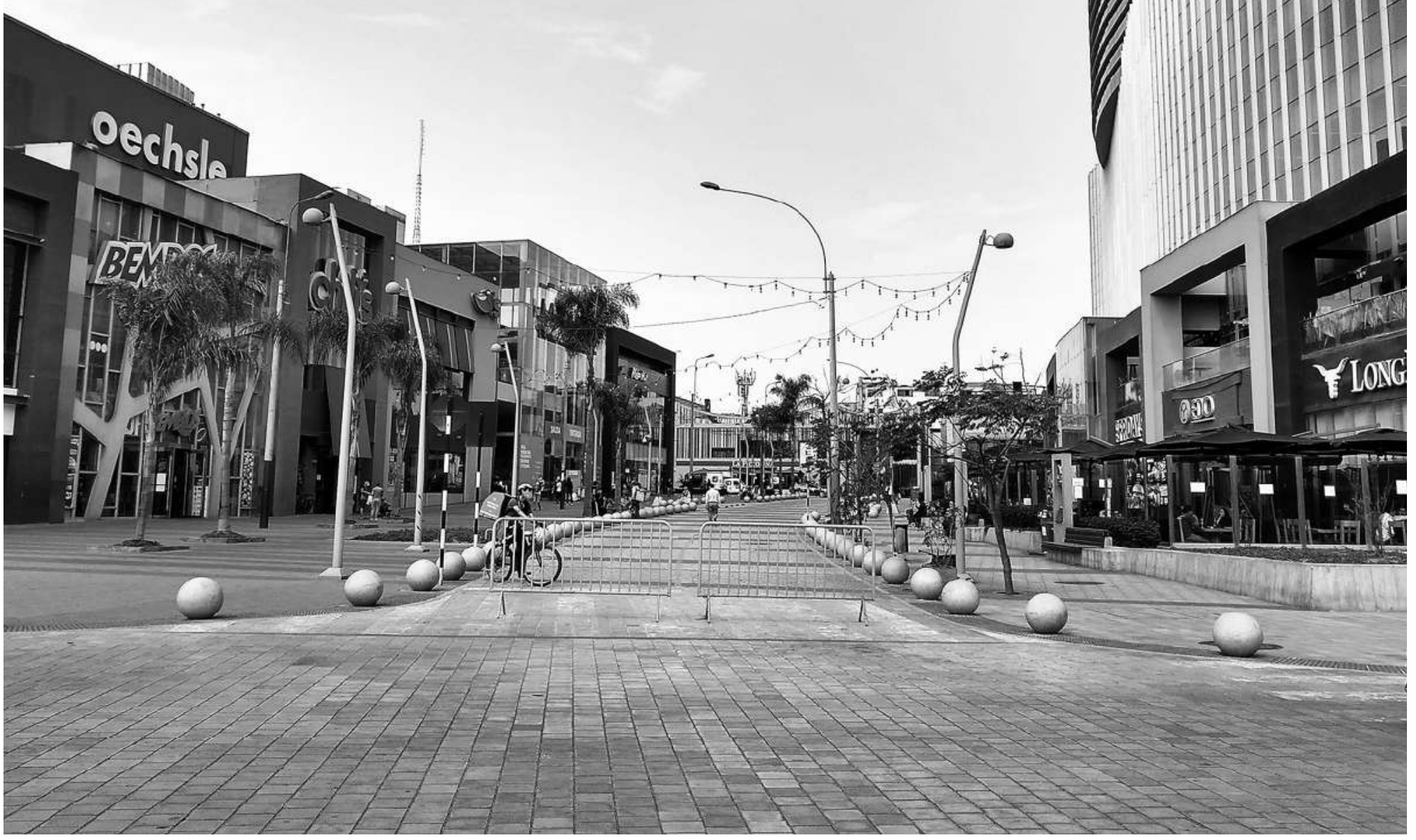

Calle Carpaccio. Distrito de San Borja. Lima. Foto Felipe Chumpitaz M., 2020

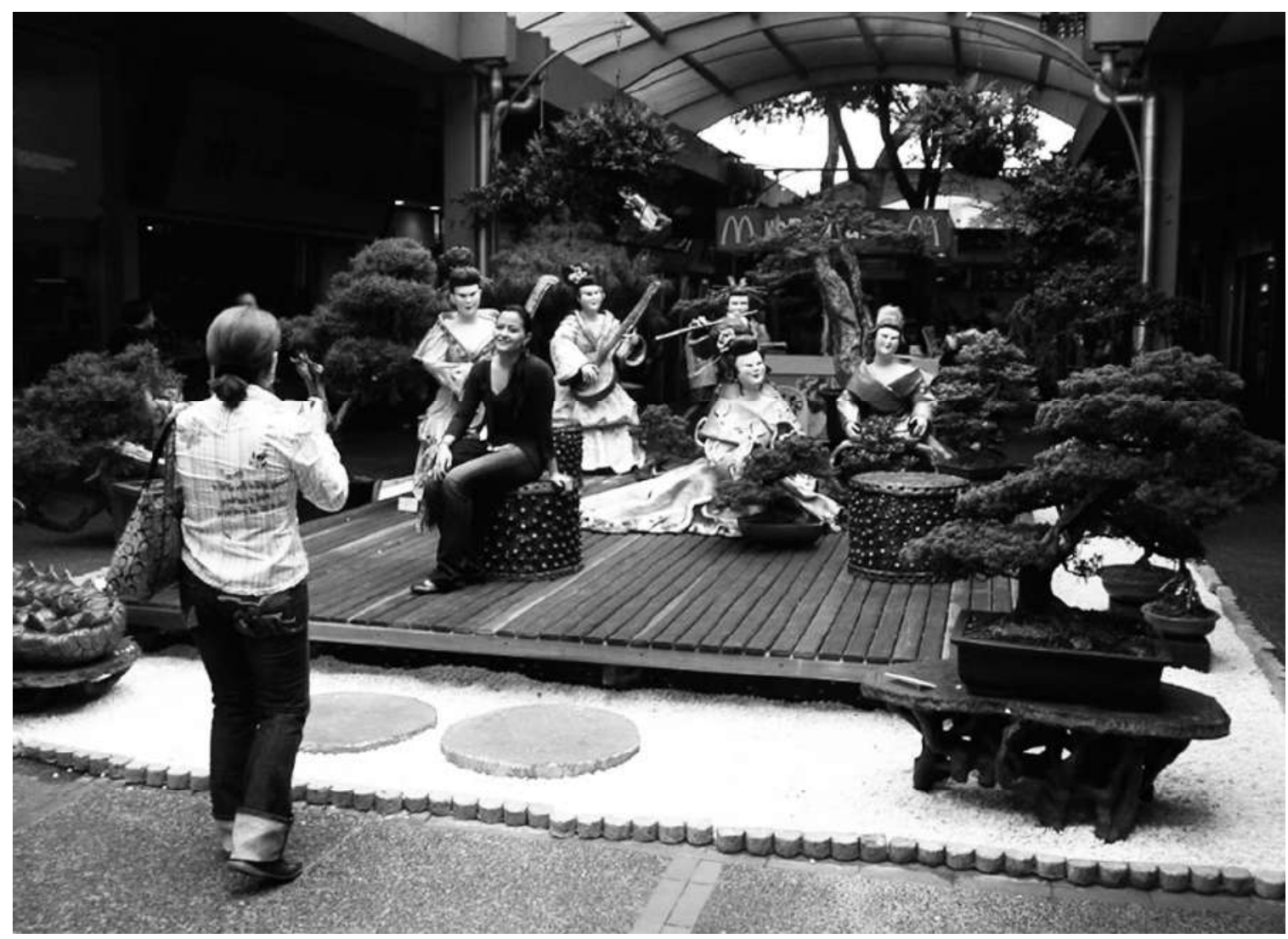


Consiste, básicamente, en el desarrollo de actividades ligadas al teatro, en calles, plazas y centros comerciales durante aproximadamente dos semanas, en las cuales la comunidad bogotana puede disfrutar de espectáculos internacionales en diferentes puntos de la ciudad, tanto en espacios públicos como en espacios comerciales abiertos o techados, en forma simultánea, sin distinción alguna de la condición económica o nivel de estrato como se le denomina en Colombia.

La iniciativa, si bien es cierto fue privada, dinamizó el uso del espacio público, generando traslados peatonales y vehiculares indistintos hacia puntos de concentración de la ciudad, en los que aparte del evento principal, se daban actividades complementarias previas y posteriores, como exposiciones, conversatorios y actividades de esparcimiento, en condiciones de confort físico y seguridad para los espectadores, propiciando así un efecto de socialización democrática, toda vez que no estaba dirigida exclusivamente a un sector o el hecho de que en un determinado punto podía darse la confluencia de personas de diferente procedencia. Esto, además, genera tradición y comienza a formar parte del acervo cultural de la ciudad, fortaleciendo la relación entre el individuo, su historia y su espacio, sea público, identificado en calles y plazas; o privado, representado generalmente por centros comerciales.

Otro caso a destacar, corresponde a los proyectos privados en los que la concentración de locales comerciales, homogéneos en el servicio que brindan y agrupados en determinados ejes de la ciudad, sin responder constructivamente al concepto de un centro comercial cerrado, aportan dentro de sus terrenos componentes urbanos, proponiendo calles y plazas que estructuran una zonificación predominante $y$, si bien responden eficientemente a sus intereses económicos, no son menos valiosos en el tratamiento de la dinámica humana que hace uso de ellos, configurando un espacio ordenado y variable que otorga las libertades de un espacio público. Esto requiere, además de la atención especial del ente normativo que, validando la calidad de la propuesta, concede las facilidades que permitan la factibilidad edilicia.

Finalmente, señalar formas de trabajo mancomunado a tomarse en cuenta, cuando la ciudad carece de espacios públicos apropiados en cantidad y dimensión para determinadas actividades, por ejemplo, considerar la pertinencia de ferias o exposiciones de diferente índole cultural. Se han dado casos en los que los centros comerciales ceden gratuitamente sus áreas de expansión a eventos distritales o metropolitanos con el fin de brindar al ciudadano la oportunidad de ejercer actividades, facultados por sus derechos y beneficios más allá de la obligación tácita de compra.

¿A qué nos llevan estas referencias? A considerar posible una relación de armonía y mutuo beneficio, entre el manejo del espacio público y los aportes que los centros comerciales puedan brindar a la ciudad, aun cuando estemos hablando de dos cosas totalmente distintas en sus propósitos. La compatibilización permanente, temporal o periódica de funciones, puede enriquecer la gama de opciones que se le ofrecerían a la colectividad. Por otra parte, no debemos olvidar que, en condiciones adecuadas de planificación, el centro comercial puede convertirse en un indicador de desarrollo sectorial y, a la vez, de mejora en el tratamiento del espacio urbano, a partir de un manejo retributivo adecuado de las rentas que le genera a la municipalidad que lo norma. Esto no exime al gobierno municipal de su obligación con el espacio público y el compromiso con los vecinos, que no se limita a los ingresos que genera el sector privado; todo lo contrario, lo debe estimular a un honrado manejo de los recursos públicos para desarrollar propuestas dirigidas a una colectividad que, como ente vivo, es dinámica, cambiante y variada en la amplitud de sus diferencias económicas y culturales, asumiendo el deber permanente de contrarrestar o anular cualquier riesgo de marginación.

\section{La satanización de la tipología}

Es casi un lugar común opinar respecto al equivocado comportamiento de las per- 
sonas cuando, en su derecho de elección, optan por el uso de espacios comerciales en vez del espacio público. ${ }^{3}$ Hay casos en los que incluso se llega a mencionar el término "ciudad enferma", acertando en el diagnóstico, pero no en el tratamiento. Esto revela una miopía crónica para identificar, en primer lugar, el problema y su magnitud y, en segunda instancia, la solución, que no es única ni atemporal, sino más bien compleja y coyuntural. El retail representado por uno de sus prototipos, los centros comerciales, seguirá actuando con agresivas estrategias dentro de sus linderos de propiedad. Esto debería representar una fracción de la adecuada funcionalidad de una ciudad, bajo ningún punto de vista, una piedra en el zapato.

Como profesionales preparados para participar de equipos multidisciplinarios que den soluciones, debemos asumir con cierta dosis de sacrificio y espíritu de lucha el reto de hacer realidad un objetivo excepcional, y, además, la responsabilidad de proponer, gestionar y ejecutar obras, que formando parte de un plan, consoliden las condiciones adecuadas para la ocupación y el uso del suelo, incluyendo los cambios de zonificación que exija el crecimiento y evolución de una ciudad. La criticada organización de los Juegos Panamericanos 2019 constituyó, en un tema poco comentado, la desaprovechada oportunidad de darle a Lima un impulso en su consolidación como urbe, lo que se debe simple y llanamente a la ausencia de un plan, disponible a largo plazo, debidamente concertado y aprobado para las próximas décadas, respaldado por un sólido músculo financiero.

No es ni será fácil enfrentarse a un poder inmobiliario desmedidamente rentista, respaldado por leyes y normas con nombre propio que pretenden hacernos creer que interpretan debidamente los reglamentos, respaldados por una administración que supuestamente intenta replantear el tráfico vehicular normando debidamente el transporte público y privado, convocando a la ciudadanía para una participación comprometida y de lucha contra la delincuen-

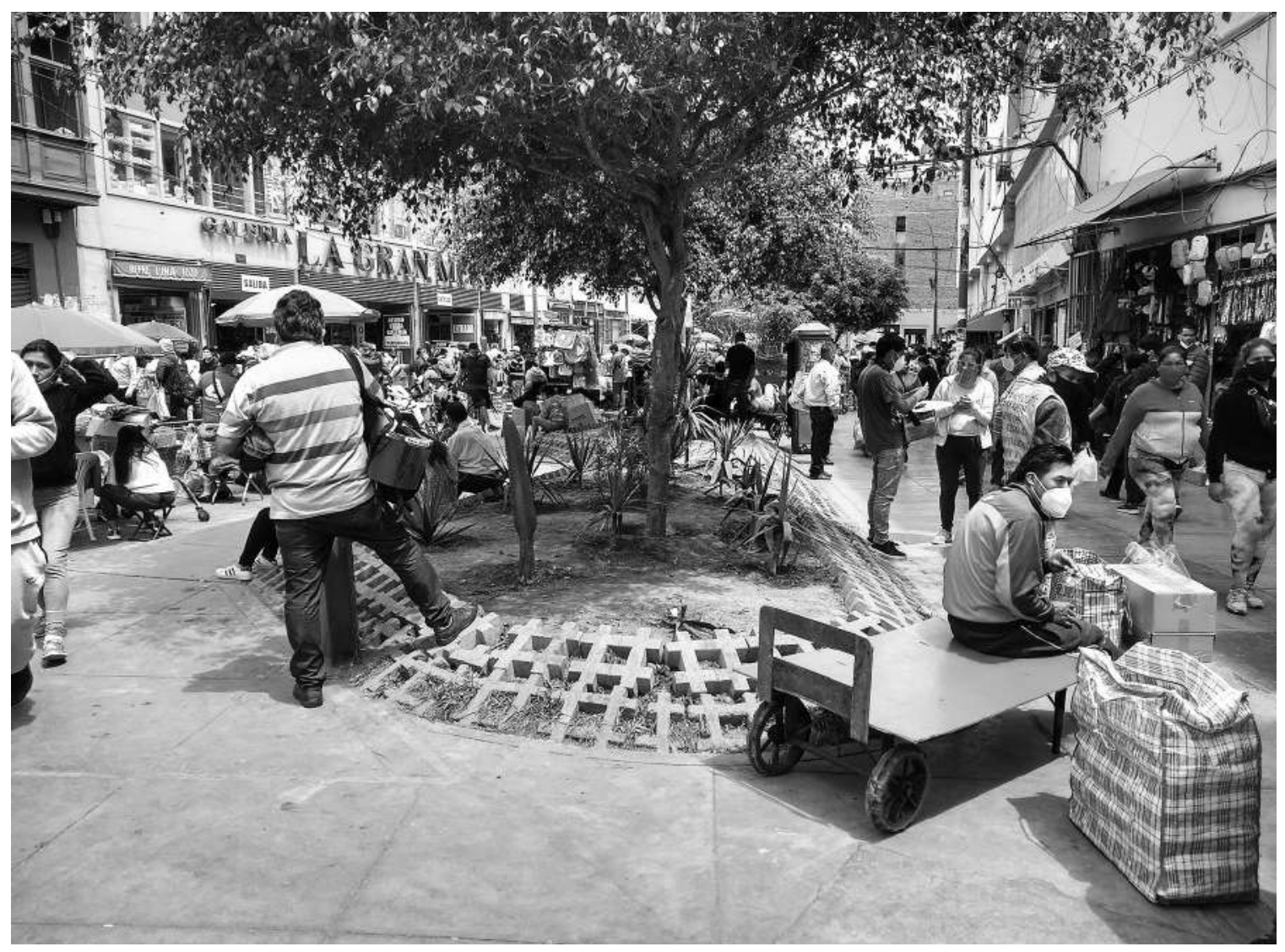

Jirón Andahuaylas. Mercado Central. Lima. Foto Felipe Chumpitaz M., 2020 
cia. Pero, se pasa por alto que el compromiso debe ser integral e integrador, por etapas, con hitos de evaluación a corto, mediano y largo plazo, sellado en piedra, para que los afanes mesiánicos de las nuevas autoridades, cada cuatro o cinco años, no interrumpan, bloqueen ni desechen por ignorancia, ineficiencia o corrupción el desarrollo sostenido de los procesos reivindicativos de una ciudad que los reclama a gritos y que hoy se conforma con lo que le ofrecen, con todas sus ventajas y desventajas, los centros comerciales.

\section{El centro comercial como una alternativa al comercio informal}

La proliferación del comercio ambulante informal en calles y avenidas de distritos consolidados, amparados por el carácter económico de países en desarrollo y, en algunos casos, por mafias muy bien organizadas, constituye un fenómeno depredador del espacio urbano, transgrediendo todas las normas que velan por su cuidado. Ante una circunstancia como esta, la primera medida es su erradicación, utilizando procedimientos legales. Sin embargo, ante la ineficiencia de los resultados, la autoridad se ve obligada a un cambio de estrategia que, para no recurrir a métodos violentos, debería propiciar la búsqueda de alternativas para una reubicación. No es un secreto que un alto porcentaje de esta informalidad está dispuesta a regularizar su situación si tal proceso no fuera tan complicado en su tramitología y exigencia, que inclusive afecta al sector formal.

Esta es una problemática que atraviesa varios estamentos de la normatividad del Estado, cuya solución implica medidas de la misma magnitud, por lo que, en lo que respecta a las respuestas desde el manejo distrital, consideramos posible que los gobiernos locales puedan conceder, dentro de sus planes de desarrollo urbano, facilidades $y$, por qué no, ventajas a quienes pretendan invertir o posean terrenos para resolver la instalación de este tipo de comercio. Se han dado casos, en otras latitudes latinoamericanas, en los que una eficiente gestión edil ha permitido transformar la energía del emprendimiento informal en la pujante fuerza que requiere la nueva etapa en su desarrollo comercial. Estos procedimientos, en términos legales, buscan simplificar los innumerables pasos para acceder a la formalidad, esencialmente documentaria; pero, en el ámbito físico, es necesario investigar, normar y propiciar la implementación de tipologías, incluyendo los centros comerciales que respondan a la demanda de los empresarios emergentes en una situación de conflicto. Aun cuando pudiera surgir escepticismo en propuestas de este tipo, abundan los ejemplos de resultados exitosos, que ciertamente tuvieron que enfrentar la dificultad de los primeros pasos, pero con el tiempo se fueron consolidando en realidades incuestionables. Sin embargo, una vez más, tenemos que insistir en que la respuesta no es distrital, debe ser a nivel de toda la ciudad y, dependiendo de la magnitud de esta, podría escalar a nivel regional o nacional.

La importancia de la conciliación de voluntades, la modificación de los reglamentos, casi siempre excesivamente condicionantes, la fortaleza de una financiación segura y prolongada y el reforzamiento de algunas condiciones operativas como la seguridad y otros servicios, podrían determinar el éxito o el fracaso del proyecto. Al fin y al cabo, la solidez y eficiencia de un espacio público que se consolida en forma paralela con la estabilidad operativa de ex-informales en poder desarrollar sus actividades de venta en locales adecuadamente acondicionados y no en la vía pública, justifica cualquier esfuerzo de las partes en llevar la relación autoridad-comerciante al nivel más óptimo de coordinación y coexistencia.

\section{La era post COVID}

Hoy, en tiempo de pandemia, sin poder precisar cuánto durará, los centros comerciales asumen nuevos retos, porque además de las precauciones que se requieren, priorizando los espacios abiertos donde se corren menos riesgos que en los cerrados por la acción recirculante (oh ironía) precisamente de los equipos de aire acondicionado, la realidad del retail ha detectado la necesidad de una revisión de la eficiencia 


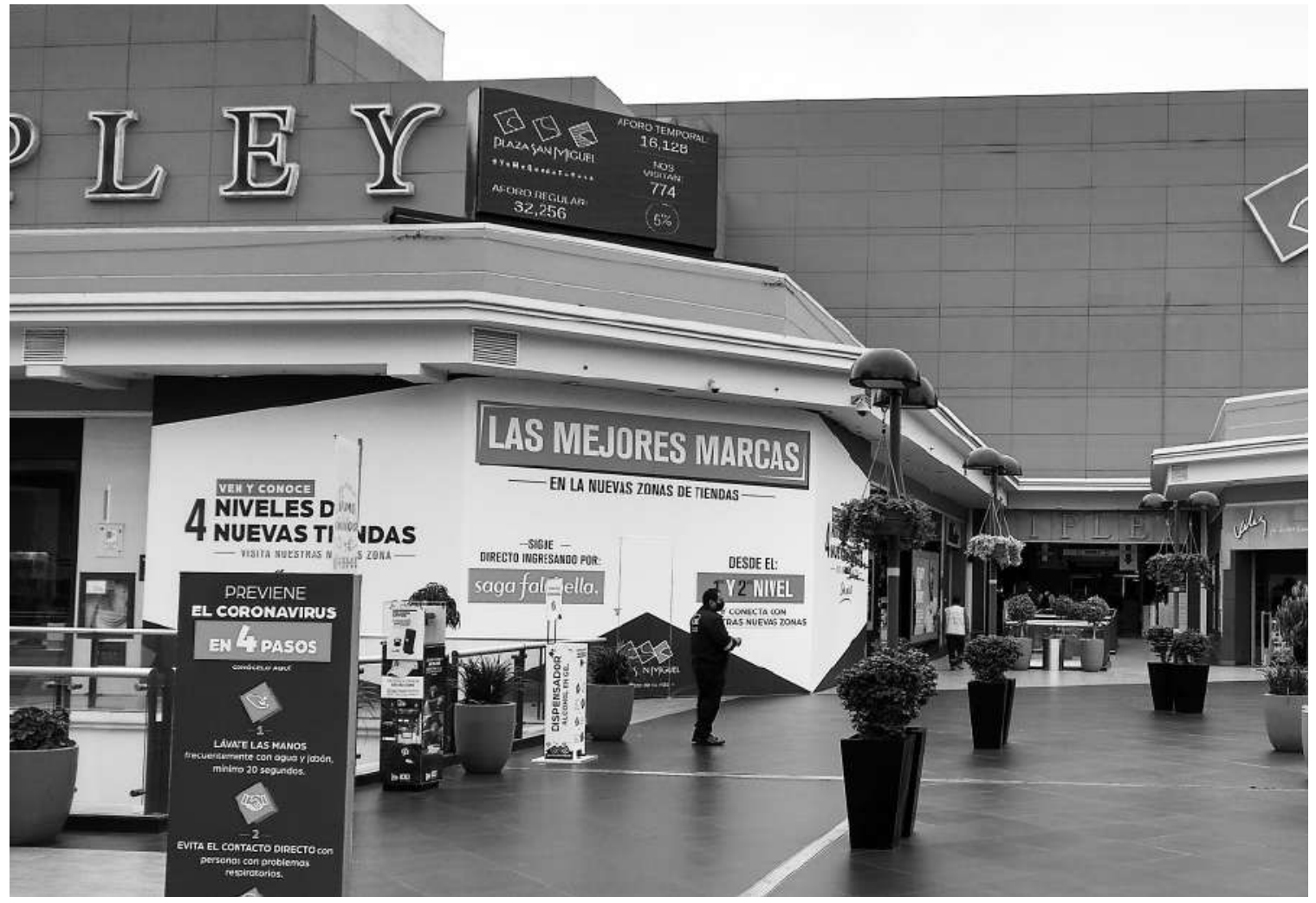

Centro Comercial Plaza San Miguel. Lima. Foto Felipe Chumpitaz M., 2020

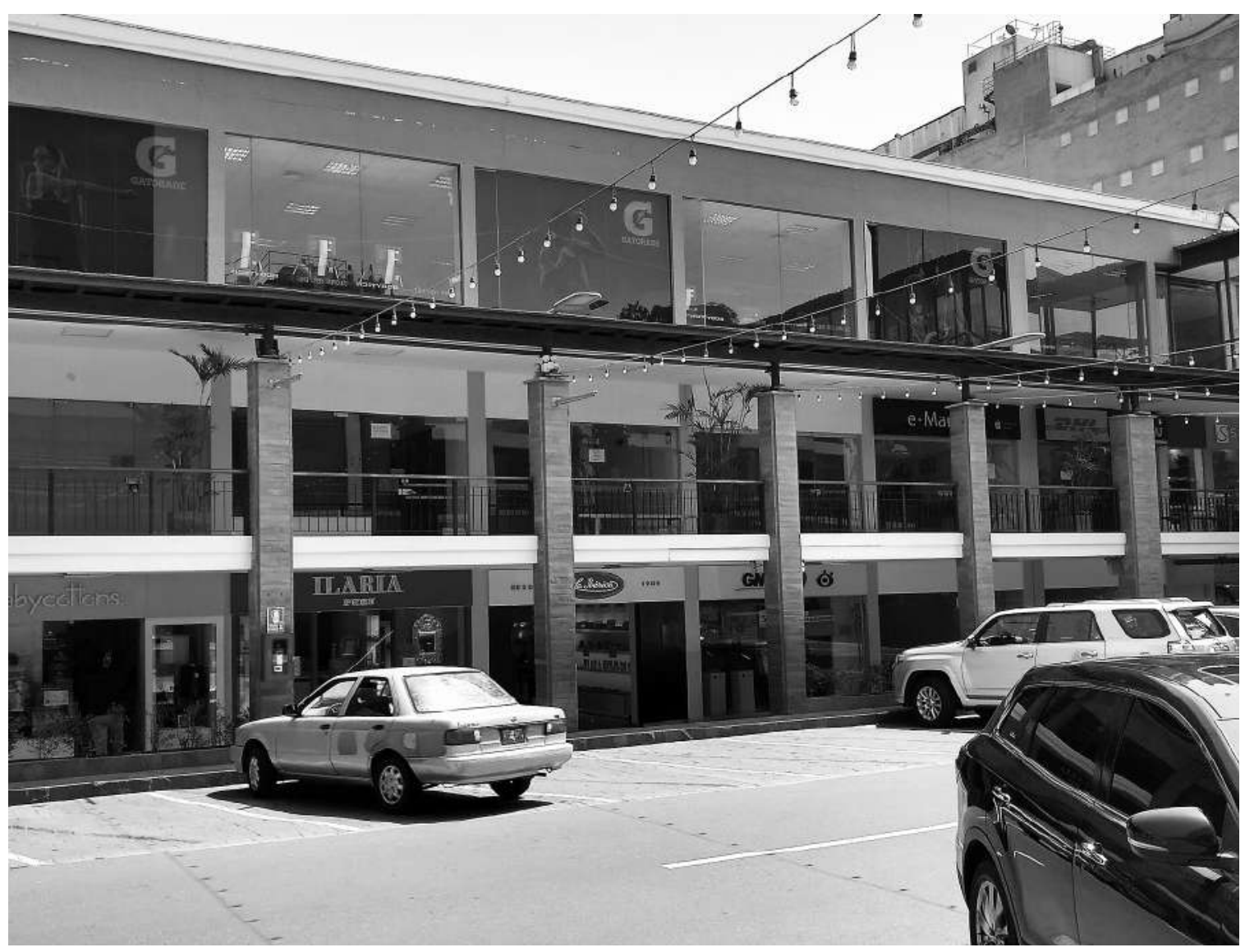

Centro Comercia El Polo. Lima. Foto Felipe Chumpitaz M., 2020. 


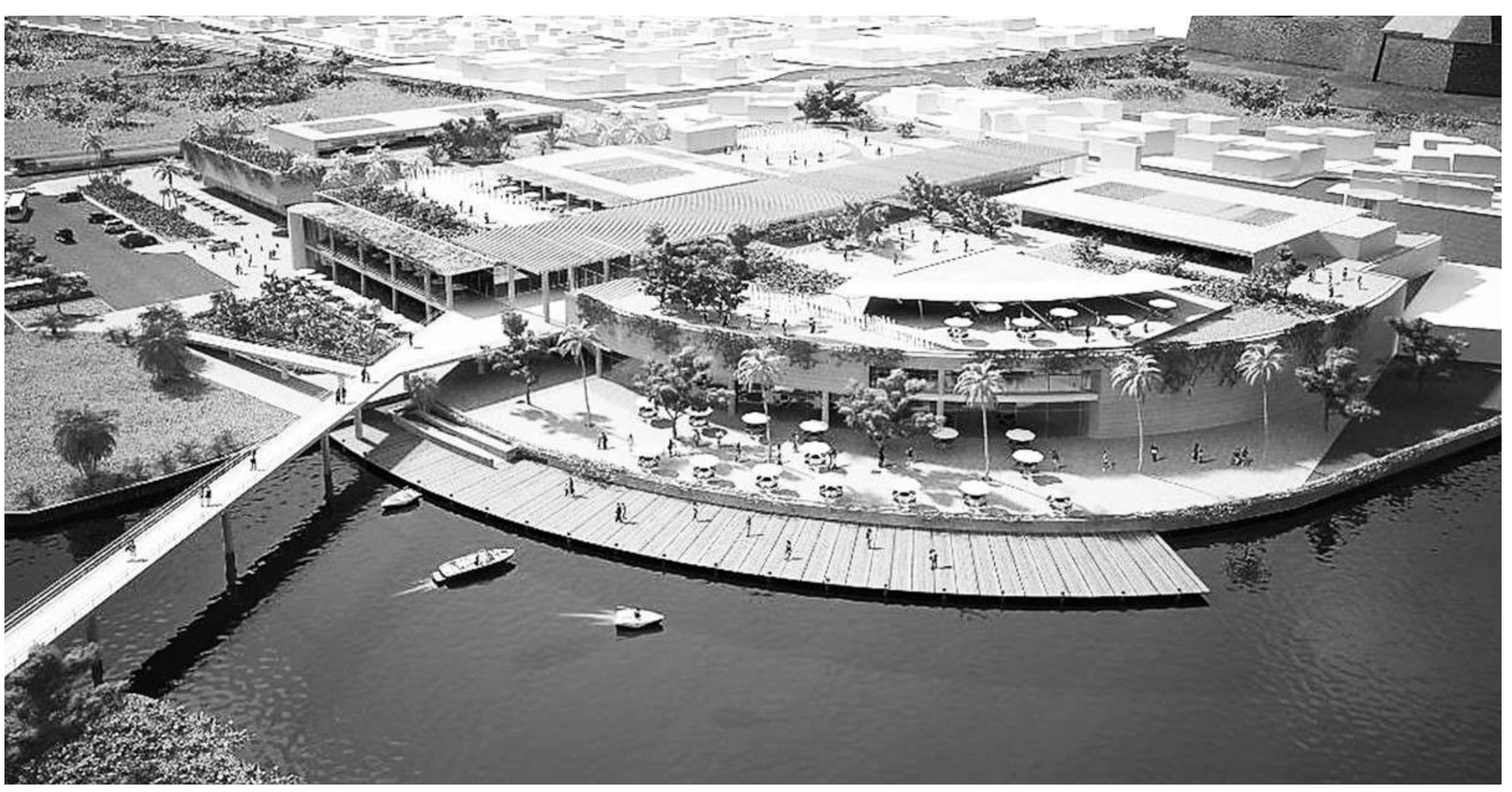

Proyecto Cartagena. Imagen del proyecto, 2012.

en la propuesta de las grandes superficies (tiendas ancla o similar), por lo que, podrían estarse generando remanentes que deben ser reutilizados de una manera audaz para que los valores comerciales no se alineen en una curva descendente.

El reto resulta interesante, porque la falencia de espacios públicos adecuados abre una veta profunda en las opciones de atracción a un público que, aunque cada vez con menor poder adquisitivo, generará un "tráfico" que es el mar donde se da la ganancia de los mejores pescadores. Es así que irán surgiendo más y mejores patios de comida, así como entidades financieras con horarios más favorables para la gente que cumple una jornada de trabajo. La pretendida naturaleza buscará ser cada vez menos artificial, con el costo asociado correspondiente, los centros médicos serán infaltables en los programas de diseño y los grandes espectáculos al aire libre desplazarán temporalmente al usuario de las playas de estacionamiento. Es decir, se recurrirá a toda instalación que atraiga al consumidor.
El centro comercial y, digamos más precisamente, el retail, tiene un reto muy difícil mirando al futuro, pues, por una parte, buscando extender la "experiencia de compra" desde antes y hasta después de la transacción económica, trabajara las áreas exteriores a la tiendas, planteando espacios abiertos y cubiertos, no necesariamente cerrados, que seduzcan al ciudadano por la comodidad de su uso, procurando "lo que más le guste", dentro de lo que cuentan patrones de identificación y pertenencia, basados en costumbres y hábitos históricamente adquiridos. Sin embargo, todo esto se debe compatibilizar con la imagen corporativa de cada negocio que, con la globalización, hace que una tienda de marca conocida internacionalmente deba ser igual en Hong Kong, París o Lima; y, si de nacionales se trata, sean lo más parecidas posible, de manera que, el resultado de esta obvia despersonalización podría devenir en el deshielo de la calidez con la que el consumidor fue recibido. Sin duda, una situación compleja. 
Para concluir, algunas reflexiones.

- Los centros comerciales no son espacios públicos, comenzando por un tema tan básico como su régimen de propiedad.

- Compartir ciertas condiciones de convivencia no iguala el concepto de dos o más espacios.

- Tener el acceso libre a un espacio, cuando este es privado, no implica que el uso de ese mismo espacio sea libre.

- El espacio público, en las ciudades del Perú y en Latinoamérica en general, requiere de intervenciones a largo plazo, con el compromiso de una fuerte inversión económica que demanda la coparticipación de instituciones y organismos que trascienden el ámbito municipal y que podrían constituirse en un ente autónomo, protegido de intereses particulares o acciones políticas partidarias, casi siempre cambiantes en cada evento electoral.

- La política educativa, desde la etapa infantil hasta la adultez del ciudadano-usuario, debe ser consistente y per-

\section{Notas}

1 "Han destruido nuestras ciudades y me niego a pasarle alimentos a esos desarrollos bastardos", dijo Víctor Gruen en la Conferencia en Londres de 1978, Diario Clarín.

2 Retail es un término anglosajón utilizado en países de habla hispana asociado al comercio minorista, un sector económico que engloba a empresas especializadas en el servicio uniforme de numerosos clientes o la venta masiva de productos. Se encarga de entregar servi- manente, haciendo énfasis en el civismo como instrumento para hacer del espacio público un lugar digno de habitarse.

- La formación técnica y universitaria, de cualquier índole, debe estar basada en valores que, respetando las aspiraciones personales de progreso, se contrapongan al mercantilismo imperativo de intereses particulares.

- Es en las aulas donde se puede iniciar el cambio que la ciudad necesita, con claridad y transparencia, que impida confusiones o tergiversaciones conceptuales intencionalmente direccionadas a hacernos creer, por citar un ejemplo, que un centro comercial puede ser o tener la importancia de un espacio público.

- Cada componente de la sociedad tiene una función específica y un compromiso de convivencia, conformando un conjunto integral e integrador. En la medida que cada uno cumpla con lo que le corresponda, se producirá un efecto directamente proporcional en beneficio y bienestar de todos. cios o productos al consumidor final, para su uso personal o el de su familia, con gran variedad de tiendas al por menor, con ventas directas al detalle. (Nota del editor)

3 "Si las personas eligen pasar su tiempo libre en espacios privados donde la participación de los ciudadanos está controlada y monitoreada, será en detrimento de una sociedad justa que debería ser uno de los beneficios de una próspera vida pública urbana." Annelise Grube-Cavers, Nohora Inés Carvajal Sánchez, 2014. 